\title{
O que nos dizem os Clássicos da Comunicação? Algumas questões sobre a constituição do campo
}

DOI: 10.1590/1809-58442018112

\section{Dilermando Gadelha}

(Faculdade Pan Amazônica, Coordenação Pedagógica, Curso de Comunicação Social - Habilitação em Publicidade e Propaganda. Belém - PA, Brasil. Faculdade Paraense de Ensino, Coordenação Pedagógica, Curso de Comunicação Social - Habilitação em Publicidade e Propaganda. Belém - PA, Brasil) https://orcid.org/0000-0002-1908-6110

\section{AGUIAR, Leonel; BARSOTTI, Adriana (Orgs.) Clássicos} da Comunicação - os teóricos: de Peirce a Canclini. Petrópolis: Vozes, 2017.

Desde que entramos no curso de Comunicação começamos a nos deparar com alguns nomes que nos acompanham vida afora. Principalmente a vida daqueles que resolvem seguir a carreira acadêmica na área e então, inevitavelmente, veem-se na iminência de estabelecer algum diálogo com os chamados clássicos da Comunicação. Autores cuja obra "provoca questões para o pensamento [comunicacional], o que resulta em incessantes discursos críticos sobre a sua produção teórica” (LEONEL,

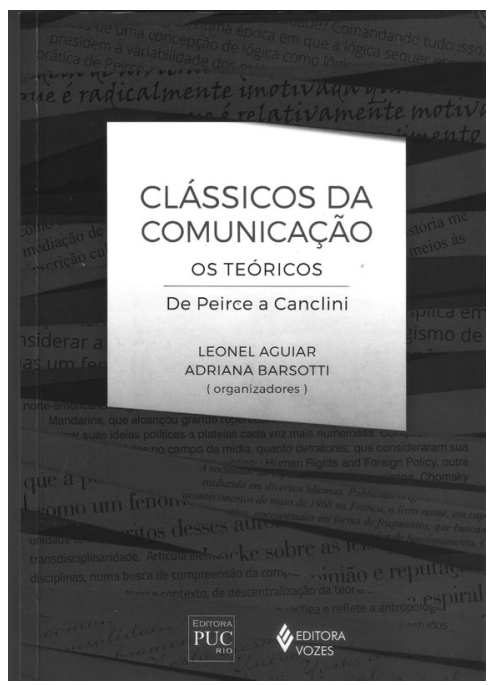
BARSOTTI, 2017, p.8).

A despeito da alcunha de clássicos da Comunicação, muitos desses nomes não possuem uma "face" ou mesmo uma biografia. Alguns deles, fundadores do campo, são recorrentes por criarem uma obra que, mesmo considerada importante, é muito superficialmente conhecida pelos pesquisadores da área. Nesse sentido, Varão (2017, p.118) reitera: "Os clássicos não devem repousar no passado, mas devem permanecer no presente, possibilitando o diálogo entre a tradição e a modernidade”.

Dialogar com os clássicos pressupõe o conhecimento não apenas de sua existência, mas também de sua biografia intelectual, de seus influenciadores e de sua influência na constituição do campo da Comunicação. Apresentar ao leitor esses percursos é um dos principais méritos do compêndio resenhado. A obra é composta por perfis de 20 pensadores de diferentes áreas do conhecimento, cuja reflexão incide recorrentemente em referências das pesquisas e em currículos dos cursos de Comunicação no Brasil. O livro aponta nomes muito variados, que vão do semioticista americano Charles Sanders Peirce ao antropólogo 
argentino Nestor Garcia-Canclini, passando por outros nomes mais ou menos conhecidos, como Noam Chomsky, Umberto Eco, Elisabeth Noelle-Neumann, Maxwell McCombs, Ferdinand Saussure e Eliseo Verón.

“Clássicos da Comunicação”, então, é um livro com diversos méritos: dentre eles a tentativa de realizar uma leitura mais aprofundada do percurso intelectual de alguns dos autores perfilados, o que contribui para a compreensão dos caminhos por eles traçados até chegar à Comunicação. Interessante saber, por exemplo, que o trabalho de Lasswell vai muito além da Teoria Hipodérmica e que o modelo de estudos da comunicação proposto pelo autor no final dos anos 1940 não foi criado para compartimentalizar as pesquisas sobre os processos midiáticos, mas sim como uma forma de, dividindo esforços entre diversos pesquisadores, possibilitar uma visão integrada e circular do fluxo comunicacional.

Ou mesmo mostrar como o pensamento de autores do cunho de Guy Debord - com uma importância não apenas acadêmica, mas também política - é bem mais amplo do que sua obra mais conhecida e uma das únicas traduzidas para o português: "A Sociedade do Espetáculo”. Em seu texto sobre o autor, Leandro e Castro (2017) alinhavam a ampla obra de Debord, que é composta não apenas de manifestos e teorias, mas também de obras artísticas e uma filmografia que busca colocar em ato muitos dos aspectos filosóficos da perspectiva debordiana sobre a sociedade do século XX.

A obra resenhada é também um fértil terreno para questionamentos: se busca fazer uma espécie de desenho da construção e consolidação da área a partir de seus autores. É interessante questionar como se deu essa seleção e, também, o que esse desenho deixa de fora. Os próprios organizadores da obra, em sua "Apresentação”, reconhecem a difícil tarefa que é selecionar apenas 20 clássicos e consideram que o processo de seleção é sempre uma perda. Nesse sentido, é peculiar notar a distribuição desses clássicos com relação às disciplinas científicas em que operam. Deles, ao menos seis trazem como área principal de formação e de pesquisas as questões das teorias da linguagem (Ferdinand Saussure, Roman Jakobson, Roland Barthes, Noam Chomsky, Umberto Eco, Eliseo Verón). Suas contribuições são importantes muito por conta dos referenciais teóricos e analíticos que disponibilizam para a leitura das linguagens midiáticas e da cultura de massa.

Afilosofia também é uma área candente entre os clássicos selecionados: Debord,Adorno, Benjamin, Peirce, Habermas, autores que, em sua reflexão filosófica, colocam em perspectiva a Comunicação em diversas dimensões, seja como processo de base para a compreensão das formas de percepção e dos processos semióticos (SANTAELLA, 2017), seja como processo social e institucional cuja irrupção no século XX provoca profundas transformações sociais. Se alguns desses autores podem ser considerados clássicos pela forma como suas reflexões são deslocadas para a compreensão dos processos comunicacionais, outros são reconhecidos pelo seu trabalho direto na criação da disciplina, dentre eles Harold Laswell, Wilbur Schram, Elizabeth Noelle-Newman, Maxwell McCombs e Jesus Martín-Barbero. 
Desse ponto de vista, principalmente ao considerarmos a grande polêmica em torno do caráter interdisciplinar da Comunicação, algumas questões suscitadas pelo livro resenhado pululam: será que as teorias da linguagem têm uma maior afinidade com o campo comunicacional? Será mais fácil fazer um deslocamento a partir dessa perspectiva do que das de outras disciplinas, como a sociologia e a antropologia, por exemplo?

Por outro lado, também se questionam as faltas, principalmente ao considerarmos que o livro foi publicado no Brasil: será que não temos ainda um clássico brasileiro? Nomes como o de Renato Ortiz costumam acompanhar os de Martín-Barbero e Canclini quando se busca pensar a existência dos Estudos Culturais Latino-Americanos e obras como “A Moderna Tradição Brasileira” são essenciais para a compreensão da formação da indústria cultural no país; por outro lado, existem pensadores nacionais cujo trabalho, ao longo de décadas, não só contribui como persegue mesmo a constituição de uma epistemologia e também de teorias da Comunicação, como os de Muniz Sodré e José Luiz Braga.

Por fim, a despeito de não ser um manual de teorias da Comunicação, "Clássicos da Comunicação!” chega aos nossos dias como um aditivo muito importante para aqueles que buscam adentrar o campo. Por outro lado, ao buscar fazer um retrato ainda que reconhecidamente parcial dessa disciplina, o livro levanta uma série de questões que contribuem para refletirmos sobre o que consideramos, aqui no Brasil, ser a área da Comunicação.

\section{Referências}

AGUIAR, L.; BARSOTTI, A. (Orgs.). Clássicos da Comunicação - os teóricos: de Peirce a Canclini. Petrópolis: Vozes, 2017. p. 256-276

LEANDRO, A.; CASTRO, I. Guy Debord (1931-1944). AGUIAR, L.; BARSOTTI, A. (Orgs.). Clássicos da Comunicação - os teóricos: de Peirce a Canclini. Petrópolis: Vozes, 2017. p. 256-276.

SANTAELLA, L. Charles Sanders Peirce (1839-1914). In: AGUIAR, L.; BARSOTTI, A. (Orgs.). Clássicos da Comunicação - os teóricos: de Peirce a Canclini. Petrópolis: Vozes, 2017. p. 20-35.

VARÃO, R. Harold Lasswell (1902-1978). In: AGUIAR, L.; BARSOTTI, A. (Orgs.). Clássicos da Comunicação - os teóricos: de Peirce a Canclini. Petrópolis: Vozes, 2017. p. 106-127.

\section{Dilermando Gadelha}

Professor dos cursos de Comunicação Social (FAPAN/FAPEN). Mestre em Ciências da Comunicação (PPGCOM/UFPA) e graduado em Comunicação Social - Jornalismo (FACOM/UFPA). E-mail: dilermandogadelha@ufpa.br.

Recebido em: 19.09.2017

Este artigo é publicado em acesso aberto (Open Access) sob a licença Creative Commons Attribution Non-Commercial (CC-BY-NC), que permite uso, distribuição e reprodução em qualquer meio, sem restrições, desde que sem fins comerciais e que o trabalho original seja corretamente citado. 